\title{
CARACTERIZAÇÃO DO ABASTECIMENTO DE MADEIRA SERRADA COMERCIALIZADA NO MUNICÍPIO DE FLORIANÓPOLIS-SC
}

\author{
Renato Cesar Gonçalves Robert ${ }^{1}$, Adriana da Silva Santos ${ }^{2}$, Leandro Duarte dos Santos ${ }^{3}$, \\ Alfredo Celso Fantini ${ }^{4}$

\begin{abstract}
${ }^{1}$ Eng. Florestal, M.Sc., Depto. de Engenharia e Tecnologia Florestal, UFPR, Curitiba, PR, Brasil - renatorobert@ufpr.br ${ }^{2}$ Enga. Florestal, Especialista, Mestranda em Agroecossistemas, UFSC, Florianópolis, SC, Brasil - anadris@ gmail.com ${ }^{3}$ Eng. Florestal, Mestrando em Engenharia Florestal, UFPR, Curitiba, PR, Brasil - leduartesantos@ yahoo.com.br
\end{abstract} \\ ${ }^{4}$ Eng. Agrônomo, Dr., Núcleo de Pesquisas em Florestas Tropicais, UFSC, Florianópolis, SC, Brasil - afantini@ @cca.ufsc.br
}

Recebido para publicação: 13/09/2010 - Aceito para publicação: 26/10/2011

\begin{abstract}
Este estudo teve como objetivo diagnosticar a quantidade e a procedência da madeira serrada comercializada na cidade de Florianópolis, em Santa Catarina. Foi realizado o levantamento de informações junto aos estabelecimentos de venda de madeira serrada no município, obtendo-se dados referentes à procedência da madeira serrada comercializada, o volume e as principais espécies exóticas e nativas existentes no mercado, além da distância média dos principais fornecedores até o mercado consumidor de Florianópolis. Os resultados permitem estimar um consumo total anual de aproximadamente $12.030 \mathrm{~m}^{3}$ de madeira serrada, sendo $5.532 \mathrm{~m}^{3}$ de espécies nativas e $6.498 \mathrm{~m}^{3} \mathrm{de}$ espécies exóticas (Pinus spp. e Eucalyptus spp.). O maior percentual (63,5\%) da madeira serrada de espécies exóticas (Pinus spp. e Eucalyptus spp.) comercializada no mercado madeireiro de Florianópolis é proveniente da mesorregião Sul Catarinense, sendo os municípios de Tubarão e São Martinho os principais fornecedores, respondendo por $21 \%$ e $13 \%$, respectivamente. Observou-se ainda que a distância média entre a capital catarinense e os municípios fornecedores de espécies exóticas é de $126 \mathrm{~km}$.

Palavras-chave: Abastecimento de madeira; distância de transporte; comercialização de madeira.
\end{abstract}

\begin{abstract}
Characterization of the supply of lumber commercialized in Florianópolis, Santa Catarina, Brazil. This study aimed at understanding the logistic of the supply of lumber commercialized in the municipality of Florianópolis in Santa Catarina State. We used interviews with managers of lumber supply stores to gather data on the origin of the lumber, the volume and major tropical species commercialized, and the average distance from suppliers to the stores. The results allowed to estimate a total annual consumption of about $12,030 \mathrm{~m}^{3}$ of lumber, of which $5,532 \mathrm{~m}^{3}$ are lumber of tropical species and $6498 \mathrm{~m}^{3}$ of exotic species (pine and eucalyptus). The highest percentage of exotic species of lumber sold in the timber market of Florianópolis is from the southern region of Santa Catarina State, mainly from the municipalities of São Martinho and Tubarão. The average distance between Florianópolis and the suppliers cities is about $126 \mathrm{~km}$.

Keywords: Wood supply; origin distance; wood commercialization.
\end{abstract}

\section{INTRODUÇÃO}

O Brasil possui aproximadamente 7 milhões de hectares de florestas plantadas, 93,4\% dos quais com espécies dos gêneros Eucalyptus e Pinus. O restante da área é plantada principalmente com Acacia spp., Tectona sp. e Araucaria angustifolia (Bert.) O. Ktze. A área de floresta plantada com os gêneros Eucalyptus e Pinus é de 6.510.693 ha, segundo a Associação Brasileira de Florestas Plantadas (ABRAF), e corresponde a $1,3 \%$ do total da área florestada do país e apenas $0,8 \%$ da área da sua superfície total (ABRAF, 2011; BRASIL, 2010).

Em relação a 2009, a área de plantios florestais aumentou 3,2\%. No período entre 2005 e 2010, o crescimento acumulado foi de $23 \%$, ou seja, $3,5 \%$ ao ano. Considerando a produção brasileira de 
serrados, no período compreendido entre 2000 e 2010, a taxa de crescimento médio anual foi de $1,7 \%$ (ABRAF, 2011).

Nas últimas quatro décadas, as florestas plantadas estiveram concentradas principalmente nas regiões Sul e Sudeste do país. Entretanto, nos últimos dez anos, novos plantios vêm ganhando destaque no cenário nacional de florestas plantadas, devido à expansão de novas fronteiras por parte de algumas empresas nas regiões Nordeste, Norte e Centro-Oeste.

Considerando-se as características das espécies dos gêneros Pinus e Eucalyptus, não é surpreendente a rápida disseminação do seu uso em projetos de reflorestamento para fins comerciais, com destaque aos fantásticos incrementos em volume de madeira alcançados, devido principalmente ao sucesso de programas de melhoramento genético pelos quais passaram.

Na região do bioma Mata Atlântica, as formações florestais secundárias formam a maior parte da cobertura florestal remanescente. Essas florestas são vistas, de maneira geral, como de pouco valor para o propósito de produção de madeira. No entanto a região já foi abundante em espécies produtoras de madeiras nobres, como Araucaria angustifolia. Em Santa Catarina, por exemplo, a exploração de florestas nativas chegou a representar 30\% do Produto Interno Bruto (PIB) no ano de 1946 (BET, 1997).

Apesar da abundância das florestas secundárias no estado e da abundância de espécies produtoras de madeira nelas existente, esses ecossistemas têm recebido pouca atenção para o propósito de produção. $\mathrm{O}$ valor de mercado da madeira de espécies presentes nessas florestas provavelmente nunca se realizou porque, por muito tempo, houve suficiente suprimento de madeiras nobres alimentado pelo rápido processo de desmatamento em toda a região e também porque, após o esgotamento destas, a oferta de madeiras com baixo preço vindas da Amazônia e a introdução de exóticas, como pínus e eucalipto, cobriu a demanda regional (FANTINI; SIMINSKI, 2007).

No início da década de 1940, a madeira proporcionou a geração de muitos empregos diretos e indiretos e possibilitou o desenvolvimento de muitos municípios, uma vez que esse produto florestal representava mais de $20 \%$ do valor total das exportações do estado (THOMÉ, 1995). Posteriormente, no período de 1950-1960, a madeira passou a representar 50\% do volume exportado pelo estado (REITZ et al., 1978).

Com a implantação de reflorestamentos baseados nos incentivos fiscais, grandes extensões de florestas foram plantadas nas regiões Sul e Sudeste. Com a manutenção de florestas de coníferas na região Sul, iniciou-se uma nova etapa para a indústria madeireira, que passou a se basear numa fonte de matériaprima cujo plantio utiliza uma espécie de rápido crescimento. Com isso, a madeira proveniente de povoamentos do gênero Pinus se transformou na principal fonte de matéria-prima para a indústria de transformação primária localizada na região Sul (LEÃO, 2000).

Com relação ao setor moveleiro, a região Sul foi líder na exportação de móveis, realizando $80,32 \%$ de toda exportação do setor mobiliário do país no ano de 2005. O estado de Santa Catarina foi responsável pelo maior volume de exportações da indústria moveleira, com 43,5\% do total (ASSOCIAÇÃ̃O BRASILEIRA DAS INDÚSTRIAS DO MOBILIÁRIO (ABIMÓVEL), 2006).

A indústria catarinense de base florestal processa por ano cerca de 15 milhões de $\mathrm{m}^{3}$ de toras de madeira, produção sustentada por 650 mil ha de florestas plantadas no estado, representando uma área de pouco mais de $10 \%$ da área plantada com os gêneros Pinus e Eucalyptus no país. Esses dados conferem a Santa Catarina um lugar de destaque no cenário florestal brasileiro, como um importante polo de produção e exportação de madeira, papel e móveis do país (EMPRESA DE PESQUISA AGROPECUÁRIA E EXTENSÃO RURAL DE SANTA CATARINA (EPAGRI), 2010).

Contudo, é notória a ausência de grandes maciços florestais destinados à produção de madeira na região de Florianópolis em contrapartida ao crescente desenvolvimento da região e suposto aumento da demanda pelo produto. Assim, informações mais detalhadas sobre o panorama do abastecimento de madeira da capital catarinense seriam estratégicas para as ações presentes e futuras que visem ao desenvolvimento regional, bem como para o desenvolvimento de alternativas referentes à logística de abastecimento e distribuição do mercado madeireiro local.

Os municípios de Florianópolis, São José, Biguaçu e Palhoça são os detentores dos maiores valores do PIB da Mesorregião da Grande Florianópolis, com destaque para a capital catarinense, Florianópolis, que ocupa a terceira posição no ranking estadual. Além disso, esse município possui destaque com relação ao aumento de construções e obras de engenharia civil, que podem garantir ao 
mercado de madeira serrada bons atrativos (INSTITUTO BRASILEIRO DE GEOGRAFIA E ESTATÍSTICA (IBGE), 2009).

Nesse sentido, este estudo teve como objetivo diagnosticar a quantidade e a procedência da madeira serrada que é comercializada no mercado varejista e atacadista na capital do estado de Santa Catarina, tanto de madeira de espécies dos gêneros Pinus e Eucalyptus como de espécies tropicais brasileiras.

\section{MATERIAL E MÉTODOS}

\section{Área de estudo}

O trabalho foi desenvolvido no município de Florianópolis, capital do estado de Santa Catarina, cuja extensão territorial total é de $433,32 \mathrm{~km}^{2}$, dos quais $12,1 \mathrm{~km}^{2}$ compõem a parte continental do município.

Além do distrito-sede (centro), outros 11 distritos compõem o município: Barra da Lagoa, Cachoeira do Bom Jesus, Campeche, Canasvieiras, Ingleses do Rio Vermelho, Lagoa da Conceição, Pântano do Sul, Ratones, Ribeirão da Ilha, Santo Antônio de Lisboa e São João do Rio Vermelho. O distrito-sede destaca-se com maior população (aproximadamente 213.600 habitantes), pois, além de conter mais bairros, abrange os mais populosos do continente e da ilha (INSTITUTO DE PLANEJAMENTO URBANO DE FLORIANÓPOLIS (IPUF), 2002).

O município possui cerca de 397.000 habitantes e um PIB per capita de R $\$ 17.907$. A economia está alicerçada nas atividades de prestação de serviços públicos, comércio, engenharia, indústria de transformação e turismo. Recentemente, grandes investimentos têm sido realizados para expandir o setor têxtil e de informática. No entanto, Florianópolis é a única das capitais brasileiras que não ocupa a primeira posição em relação à contribuição do PIB para o respectivo estado, sendo superada pelos municípios de Joinville e Itajaí (IBGE, 2009).

Conforme o ranking do Índice de Desenvolvimento Humano dos municípios brasileiros (IDHM) estabelecido pela Organização das Nações Unidas (ONU), Florianópolis foi apontada como a $1^{\text {a }}$ capital brasileira e $4^{\mathrm{a}}$ cidade, com um IDH de 0,875 (PROGRAMA DE DESENVOLVIMENTO DAS NAÇÕES UNIDAS (PNUD), 2000).

\section{Coleta de dados}

Os dados foram coletados através de entrevistas semiestruturadas realizadas junto a proprietários e gerentes de madeireiras, totalizando 30 entrevistas. Durante as entrevistas, foram levantadas informações acerca das espécies de madeira serrada comercializadas (exóticas e nativas), volume e município de procedência.

Para efeito de amostragem, consideraram-se somente os estabelecimentos comerciais madeireiros, ou seja, foram excluídos os estabelecimentos em que o comércio de madeiras é realizado em conjunto com outros materiais de construção. Foram identificadas 37 madeireiras, assumindo-se esse número como o tamanho da população pesquisada, das quais 30 foram sorteadas para a realização das entrevistas, distribuídas nas principais ruas, avenidas e rodovias localizadas nos distritos do município. $\mathrm{O}$ tamanho da amostra resultou em um erro amostral de $8 \%$, segundo cálculo realizado através do método proposto por Barbetta (2006).

Foram levantados dados junto aos estabelecimentos de comércio de madeira serrada localizados em Florianópolis, entre outros, com o intuito de se identificar a distância média entre estes e os principais fornecedores de matéria-prima (madeira serrada). Além disso, verificaram-se as espécies de madeira adquiridas e a estimativa do consumo mensal delas pelos estabelecimentos florianopolitanos.

Os nomes das espécies florestais nativas comercializadas pelos estabelecimentos foram informados pelos entrevistados, seguindo informações do sistema de documento de origem florestal (DOF) do Instituto Brasileiro de Meio Ambiente e Recursos Naturais Renováveis (IBAMA).

Os dados obtidos foram organizados, descritos e analisados com a utilização de estatística descritiva simples, através da construção de tabelas e gráficos com o auxílio de planilha eletrônica.

Para estimar as distâncias entre o município de Florianópolis (destino da matéria-prima transportada) e os municípios fornecedores de madeira serrada (origem), apontados durante as entrevistas, foram utilizadas as informações disponíveis no website da Secretaria da Fazenda do Governo do Estado 
do Mato Grosso. Esse website é utilizado como referência para o cálculo de ICMS-transporte (Imposto sobre Operações relativas à Circulação de Mercadorias e Prestação de Serviços de Transporte Interestadual e Intermunicipal e de Comunicação). Através dele, é possível calcular a distância entre a origem e o destino da mercadoria transportada, estimando a distância de centro a centro, considerando um erro admissível de 5\%, para e entre todos os municípios do território nacional.

Conhecendo-se as distâncias entre Florianópolis e os centros dos municípios fornecedores, calculou-se a distância média dos municípios de acordo com os estabelecimentos visitados, por meio de média aritmética. Em seguida, procedeu-se ao seu agrupamento em classes, obtendo-se assim uma tabela da distribuição de frequências das distâncias médias obtidas.

\section{RESULTADOS E DISCUSSÃO}

\section{Principais espécies florestais comercializadas em Florianópolis}

A partir dos dados levantados durante as entrevistas, constatou-se que a comercialização de madeira serrada se dá principalmente com espécies dos gêneros Pinus e Eucalyptus e de 11 espécies diferentes de madeira nativa tropical, conhecidas no comércio local pelos nomes comuns ou vernaculares (Tabela 1). É importante ressaltar que, em alguns casos, esses tipos correspondem a mais de uma espécie madeireira, porque os nomes comuns podem variar entre regiões e pessoas, resultado da falta de padronização dessa nomenclatura. Um exemplo claro é o caso do angelim, nome comum atribuído a diferentes espécies dos gêneros Andira sp., Dinizia sp., Pithecellobium sp., Hymenolobium sp. e Vatairea sp.

A partir da tabela 1 é possível notar que as espécies tropicais comercializadas em Florianópolis são as comumente encontradas no mercado de varejo de madeiras nas principais cidades do país. Isso pode ser devido ao fato de o mercado consumidor ainda não demandar outras espécies que atualmente já vem sendo exploradas em planos de manejo florestal sustentável (PMFS), visto que as primeiras 25 espécies de maior volume transportado compreendem $50 \%$ do total, ou seja, o mercado ainda continua restrito a um número relativamente pequeno de espécies (IBAMA, 2010).

Tabela 1. Espécies tropicais de madeira serrada comercializadas nas madeireiras de Florianópolis.

Table 1. Timber of tropical species commercialized in Florianopolis, SC, Brazil.

\begin{tabular}{ll}
\hline Nome comum & Nome científico \\
\hline Angelim & Andira sp.; Dinizia sp.; Vatairea sp.; Pithecellobium sp.; Hymenolobium sp. \\
Angelim-pedra & Hymenolobium $\mathrm{sp}$. \\
Cambará & Vochysia sp.; Qualea sp. \\
Cedrão & Hymenolobium sp.; Cedrelinga catenaeformis D. Ducke \\
Cedrinho & Erisma uncinatum Warm. \\
Faveiro & Parkia sp. \\
Garapeira & Apuleia sp. \\
Ipê & Tabebuia sp. \\
Itaúba & Mezilaurus itauba (Meissn.) \\
Jatobá & Hymenaea courbaril L. \\
\hline
\end{tabular}

Dos estabelecimentos visitados, $70 \%$ comercializam tanto madeira serrada dos gêneros Pinus e Eucalyptus quanto de espécies tropicais. Os outros estabelecimentos são especializados no comércio de madeira serrada de espécies exóticas $(23 \%)$ ou de espécies tropicais (7\%). Esses dados revelam uma dinâmica do mercado de varejo de madeira serrada diferente daquela encontrada por Schuch et al. (2008) para os estabelecimentos madeireiros da região da Grande Florianópolis. Segundo esses autores, a maioria dos estabelecimentos é especializada no comércio de madeiras de espécies exóticas ou tropicais (46\% em cada caso) e somente $8 \%$ trabalham com ambos os grupos de espécies. Isso demonstra um avanço das madeiras de pínus e eucalipto no comércio madeireiro da região, que era abastecido exclusivamente por madeiras tropicais.

O número de espécies tropicais comercializadas por madeireira varia de um a cinco, sendo que $47 \%$ dos estabelecimentos trabalham com apenas duas espécies. Os estabelecimentos que trabalham com uma espécie representam $21 \%$ do total (Figura 1). 


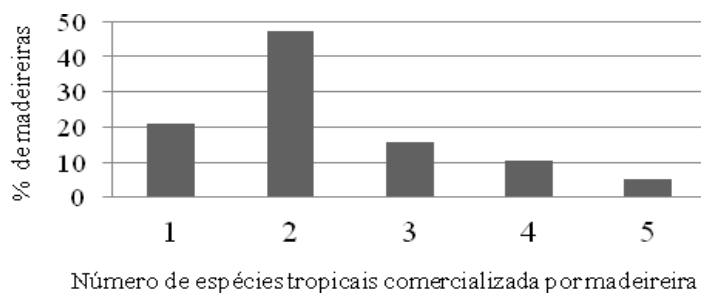

Figura 1. Distribuição de madeireiras de Florianópolis de acordo com a diversidade de espécies tropicais comercializadas.

Figure 1. Distribution of lumber suppliers in Florianópolis according to the diversity of tropical species commercialized.

A figura 1 mostra que os estabelecimentos comerciais da capital catarinense não costumam adquirir um grande número de espécies florestais. Esse efeito pode ser bastante nocivo quando avaliado a partir da necessidade do aproveitamento de espécies alternativas para o uso em PMFS, pois gera uma busca maior por determinadas espécies, causando assim uma possível escassez delas em futuras rotações de manejo florestal sustentável na Amazônia.

Observou-se ainda que, das espécies de madeira tropical comercializadas, a espécie mais frequente encontrada nos estabelecimentos especializados é o angelim, seguido pelo cambará. A madeira serrada de angelim pode ser encontrada em cerca de $31 \%$ dos estabelecimentos, seguida de cambará $(25 \%)$, angelim-pedra $(12 \%)$, cedrinho $(10 \%)$, garapeira $(6 \%)$, itaúba $(4,5 \%)$, jatobá $(4,5 \%)$ e outras espécies (7\%).

Analisando o uso das espécies florestais tropicais apresentadas anteriormente, é possível caracterizar que o consumo de madeira nativa das espécies de angelim e de cambará em Florianópolis representa cerca de $68 \%$ do total comercializado pelos estabelecimentos visitados. Essa porcentagem indica a preferência dos usuários de madeira na cidade e mais uma vez reforça a falta de diversidade de espécies comercializadas na capital catarinense.

\section{Volume de madeira serrada das principais espécies comercializadas}

Os estabelecimentos visitados informaram durante as entrevistas uma estimativa do volume mensal consumido de madeira serrada de espécies tropicais e de exóticas. Contudo, não foi possível obter o valor do volume mensal referente ao consumo de madeira tropical serrada para cada espécie comercializada, uma vez que os entrevistados informaram somente o somatório do volume mensal de todas estas.

De acordo com os dados levantados, o consumo total de madeira serrada de espécies nativas pelos estabelecimentos visitados é de $461 \mathrm{~m}^{3} /$ mês, correspondendo a $46 \%$ do total e a um consumo médio de $27,1 \mathrm{~m}^{3}$ por estabelecimento. Por sua vez, o consumo total de madeira serrada dos gêneros Pinus e Eucalyptus é de $541 \mathrm{~m}^{3} / \mathrm{mês}$, correspondendo a $54 \%$ do volume total de madeira serrada consumido mensalmente.

No entanto, apesar de $93 \%$ dos estabelecimentos visitados em Florianópolis comercializarem madeira de pínus e eucalipto, observa-se que o volume de madeira serrada de espécies tropicais ainda representa cerca de metade do volume total de madeiras comercializado no município.

Com relação ao volume de madeira nativa serrada comercializada pelas madeireiras visitadas em Florianópolis, verificou-se que a média mensal aproxima-se de $22 \mathrm{~m}^{3}$ (Tabela 2). Contudo, 9,5\% dos estabelecimentos que comercializam esse tipo de matéria-prima não informaram o volume comercializado.

Devido ao fato de os entrevistados não informarem o volume de madeira tropical serrada comercializado por espécie, houve um maior detalhamento nos dados referentes ao volume consumido das espécies exóticas, o que tornou possível realizar uma distribuição entre o volume consumido de madeira serrada de pínus, madeira serrada de eucalipto e eucalipto roliço (Figura 2). 
Tabela 2. Volume $\left(\mathrm{m}^{3} / \mathrm{mês}\right)$ de madeira serrada tropical comercializado pelas madeireiras de Florianópolis.

Table 2. Volume $\left(\mathrm{m}^{3} / \mathrm{month}\right)$ of tropical lumber species commercialized by lumber suppliers in Florianópolis-SC, Brazil.

\begin{tabular}{|c|c|}
\hline Volume ( $\left.\mathrm{m}^{3} / \mathrm{mês}\right)$ & Madeireiras (\%) \\
\hline $0 \mid-14$ & 33,3 \\
\hline $14 \mid-28$ & 23,8 \\
\hline $28 \mid-42$ & 19,0 \\
\hline $42 \mid-56$ & 4,8 \\
\hline $56 \mid-70$ & 9,5 \\
\hline Não informaram & 9,5 \\
\hline
\end{tabular}

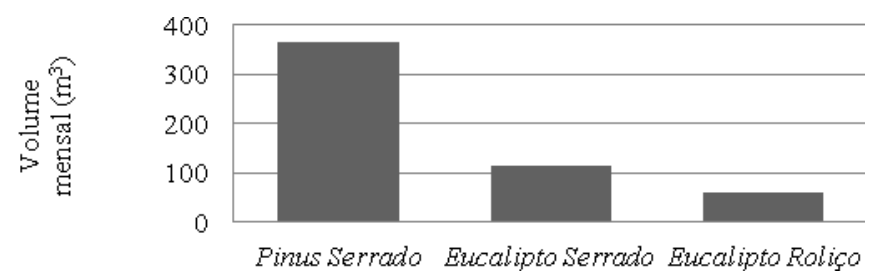

Figura 2. Volume mensal total de madeira exótica comercializado pelos estabelecimentos de Florianópolis. Figure 2. Monthly volume of pine and eucalyptus wood commercialized by lumber suppliers in Florianopolis, SC, Brazil.

Dos estabelecimentos visitados, $70 \%$ comercializam madeira serrada de pínus, totalizando um volume mensal de $354 \mathrm{~m}^{3}$, sendo o volume médio consumido de $15 \mathrm{~m}^{3}$ de madeira serrada de pínus por estabelecimento. O volume mensal consumido de eucalipto serrado e roliço é de $176 \mathrm{~m}^{3}$, sendo o volume de eucalipto serrado de $114 \mathrm{~m}^{3}$ e o de eucalipto roliço de $62 \mathrm{~m}^{3}$. O volume médio mensal de madeira de eucalipto consumido é de $33 \mathrm{~m}^{3}$ por estabelecimento.

\section{Origem da madeira serrada de espécies tropicais comercializada em Florianópolis}

Quanto à origem da madeira serrada de espécies tropicais, foi possível identificar apenas os estados de origem (Tabela 3).

Tabela 3. Estados de origem da madeira serrada de espécies tropicais comercializada em Florianópolis.

Table 3. Origin states of lumber of tropical species commercialized in Florianopolis, SC, Brazil.

\begin{tabular}{lc}
\hline Espécie & Origem \\
\hline Angelim & AC, PA, RO, MT \\
Angelim-pedra & MT, RO, PA \\
Cambará & RO, AC, PA, MT \\
Cedrão & RO \\
Cedrinho & PA, MT \\
Faveiro & RO, MT, PA \\
Garapeira & PA, MT, RO \\
Ipê & MT, RO \\
Itaúba & RO, MT, PA \\
Jatobá & MT, RO, PA \\
\hline
\end{tabular}

Observou-se que as madeireiras visitadas em Florianópolis recebem madeira serrada de espécies tropicais desde um até quatro diferentes estados da Amazônia Legal, sendo que a maior parte dos estabelecimentos (52\%) geralmente recebe o produto de apenas dois estados. O estado do Mato Grosso aparece como o maior fornecedor, com 36\%, seguido por Rondônia (28\%), Pará (25\%) e Acre (11\%). Com base nos dados, verificou-se ainda que esses estados também são responsáveis pelo fornecimento da 
maioria das espécies comercializadas, sendo a madeira de cedrão de abastecimento exclusivo do estado de Rondônia, podendo esse fato ser devido à nomenclatura utilizada pelos fornecedores.

Os estados do Mato Grosso e de Rondônia representam 64\% da procedência da madeira serrada de espécies nativas que abastece o mercado madeireiro de Florianópolis.

\section{Madeira serrada de pínus e eucalipto}

A figura 3 apresenta as mesorregiões e os municípios fornecedores de madeira serrada de espécies exóticas para Florianópolis. Nessa figura também é possível visualizar a localização do município de Florianópolis dentro da Mesorregião da Grande Florianópolis.

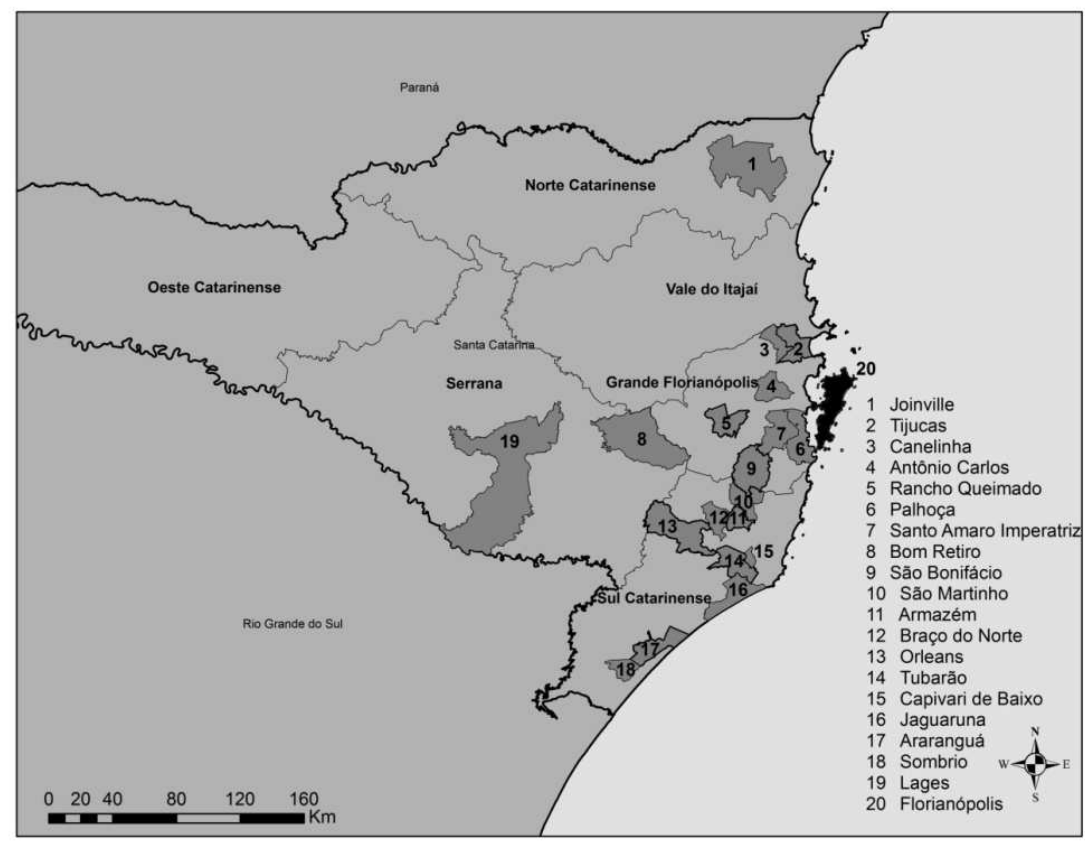

Figura 3. Mesorregiões e Municípios catarinenses fornecedores de madeira serrada de espécies dos gêneros Pinus e Eucalyptus para as madeireiras de Florianópolis.

Figure 3. Municipalities of Santa Catarina that supply lumber of Pinus and Eucalyptus species to Florianópolis.

A porcentagem de estabelecimentos madeireiros de Florianópolis que recebem madeira das mesorregiões, microrregiões e dos municípios fornecedores é apresentada na tabela 4.

Os dados referentes à origem da madeira serrada dos gêneros Pinus e Eucalyptus permitiram identificar que, do total, $96 \%$ da madeira recebida é proveniente de municípios catarinenses, sendo o restante originário de municípios do Rio Grande do Sul. De forma geral, os estabelecimentos especializados no comércio de madeira serrada da capital de Santa Catarina recebem matéria-prima de espécies desses gêneros de um a cinco municípios diferentes do estado, sendo que $38 \%$ dos estabelecimentos recebem de um único município, enquanto que $42 \%$ recebem de 3 a 5 municípios diferentes.

Não foi possível verificar os municípios fornecedores do estado do Rio Grande do Sul, com exceção de Jaquirana, único município gaúcho informado, tendo sido mencionado por $2 \%$ dos entrevistados. 
Tabela 4. Porcentagem de madeireiras que recebem madeira serrada de espécies dos gêneros Pinus e Eucalyptus e mesorregiões, microrregiões e municípios catarinenses fornecedores.

Table 4. Percentage of lumber suppliers in Florianopolis and municipalities that supply Pinus and Eucalyptus species.

\begin{tabular}{lccc}
\hline Mesorregião & Origem da madeira serrada de pínus e de eucalipto & $\begin{array}{c}\text { Madeireiras } \\
\text { consumidoras } \\
(\mathbf{\%})\end{array}$ \\
\cline { 2 - 3 } Sul Catarinense & Microrregião & Município & 21 \\
Sul Catarinense & Tubarão & Tubarão & 13 \\
Grande Florianópolis & Tubarão & São Martinho & 7 \\
Sul Catarinense & Florianópolis & Antônio Carlos & 7 \\
Grande Florianópolis & Tubarão & Armazém & 5 \\
Grande Florianópolis & Florianópolis & Santo Amaro & 5 \\
Sul Catarinense & Tabuleiro & São Bonifácio & 5 \\
Sul Catarinense & Araranguá & Araranguá & 5 \\
Grande Florianópolis & Tubarão & Braço do Norte & 4 \\
Serrana & Tijucas & Canelinha & 4 \\
Sul Catarinense & Campos de Lages & Lages & 4 \\
Grande Florianópolis & Tubarão & Palhoça & 2 \\
Grande Florianópolis & Florianópolis & Rancho Queimado & 2 \\
Grande Florianópolis & Tabuleiro & Tijucas & 2 \\
Norte Catarinense & Tijucas & Joinville & 2 \\
Serrana & Joinville & Bom Retiro & 2 \\
Sul Catarinense & Campos de Lages & Jaguaruna & 2 \\
Sul Catarinense & Tubarão & Orleans & 2 \\
Sul Catarinense & Tubarão & Sombrio & 2 \\
\hline & Araranguá & & 4 \\
\hline
\end{tabular}

Foi verificada uma pequena variação de municípios catarinenses fornecedores de matéria-prima, totalizando 19 municípios, distribuídos entre quatro mesorregiões e sete microrregiões catarinenses.

A mesorregião Sul Catarinense é a responsável pelo maior percentual (63\%) de madeira serrada de pínus e eucalipto fornecida às madeireiras da Capital, seguida pela mesorregião da Grande Florianópolis, que fornece cerca de $29 \%$. O município de Tubarão é o responsável por $21 \%$ deste fornecimento, seguido pelo município de São Martinho, com 13\%. Não existem evidências obtidas através das entrevistas da razão de o município de Tubarão e consequentemente a Mesorregião Sul serem os principais fornecedores de madeira serrada para Florianópolis, visto que a mesorregião serrana é conhecida pela aptidão de sua economia ser voltada às atividades de base florestal e madeireira.

\section{Distância média entre os principais fornecedores de madeira serrada e as madeireiras de Florianópolis}

Os estados da Amazônia Legal são os principais fornecedores de madeira serrada de espécies tropicais para o mercado doméstico nacional (SOBRAL et al, 2002). A dificuldade desta pesquisa em identificar os municípios dos estados da Amazônia Legal fornecedores de matéria-prima não permitiu estabelecer a distância média entre o comércio de madeira serrada de espécies tropicais de Florianópolis e os estados de origem.

Dessa forma, estabeleceu-se apenas a distância média entre o mercado consumidor de Florianópolis e os municípios fornecedores de madeira serrada das espécies dos Gêneros Pinus e Eucalyptus identificados por esta pesquisa (Tabela 5).

A distância média verificada neste estudo entre os municípios fornecedores de madeira serrada de pínus e eucalipto e Florianópolis foi de $126 \mathrm{~km}$. Isso é evidenciado na tabela 5, na qual a classe 3 foi a que recebeu maior porcentagem de relatos, indicando que 33\% dos estabelecimentos entrevistados em Florianópolis recebem madeira exótica de distâncias entre 92 e 137,9 km. Portanto, é possível estimar que cerca de $67 \%$ das madeireiras florianopolitanas se abastecem de madeira serrada proveniente de serrarias ou outros fornecedores localizados entre 0 a 137,9 quilômetros de distância de Florianópolis. Por outro 
lado, $12 \%$ dos fornecedores de madeira serrada (pínus e eucalipto) encontram-se distantes em média $207 \mathrm{~km}$ da capital catarinense.

Tabela 5. Distâncias entre as madeireiras de Florianópolis e os municípios fornecedores de madeira serrada de pínus e eucalipto.

Table 5. Distance between lumber suppliers in Florianopolis and the respective municipalities suppliers of pinus and eucalyptus lumber.

\begin{tabular}{lccc}
\hline Classes & $\begin{array}{c}\text { Distâncias entre fornecedores e } \\
\text { Florianópolis (km) }\end{array}$ & $\begin{array}{c}\text { Média estimada das } \\
\text { classes }\end{array}$ & $\begin{array}{c}\text { \% de madeireiras } \\
\text { consumidoras }\end{array}$ \\
\hline 1 & $0 \mid-46$ & 23 & 17 \\
2 & $46 \mid-92$ & 69 & 17 \\
3 & $92 \mid-138$ & 115 & 33 \\
4 & $138 \mid-184$ & 161 & 21 \\
5 & $184 \mid-230$ & 207 & 12 \\
\hline
\end{tabular}

\section{CONCLUSÕES}

- Os municípios de Tubarão e São Martinho são os principais fornecedores de madeira serrada dos gêneros Pinus e Eucalyptus para os estabelecimentos madeireiros de Florianópolis, respondendo por $21 \%$ e $13 \%$ do total, respectivamente.

- A mesorregião Sul Catarinense é responsável por 63,5\% do abastecimento de madeira serrada de espécies exóticas para os estabelecimentos madeireiros de Florianópolis.

- A distância média entre os municípios fornecedores de madeira serrada de pínus e eucalipto e o município de Florianópolis é de $126 \mathrm{~km}$. 1/3 dos estabelecimentos florianopolitanos recebem madeira de fornecedores localizados a uma distância média de $115 \mathrm{~km}$.

- Acre, Rondônia, Pará e Mato Grosso fornecem madeira serrada de espécies tropicais para o município de Florianópolis, sendo o estado de Mato Grosso responsável pelo maior volume (36\%).

- As principais espécies nativas comercializadas em Florianópolis são angelim e cambará.

- O consumo mensal total de madeira serrada de espécies tropicais dos estabelecimentos comerciais visitados em Florianópolis é $461 \mathrm{~m}^{3}$, enquanto que de madeira serrada de pínus e eucalipto é de $542 \mathrm{~m}^{3}$, totalizando cerca de $1.000 \mathrm{~m}^{3}$, estimando-se um consumo anual de $12.030 \mathrm{~m}^{3}$, sendo $5.532 \mathrm{~m}^{3}$ de madeira serrada tropical e $6.498 \mathrm{~m}^{3}$ de espécies exóticas.

\section{REFERÊNCIAS}

ASSOCIAÇÃO BRASILEIRA DAS INDÚSTRIAS DO MOBILIÁRIO (ABIMÓVEL). Mercado Internacional para o Produto Brasileiro. In: $3^{\circ}$ Congresso Brasileiro de Desenvolvimento Sustentável para a Indústria de Base Florestal e de Geração de Energia - CONGRESSO MADEIRA 2006. Apresentação oral. Disponível em:<http://www.abraflor.org.br/documentos/madeira2006/painel2palestra2.pdf $>$. Acesso em: 03/02/2010.

ASSOCIAÇÃO BRASILEIRA DE PRODUTORES DE FLORESTAS PLANTADAS (ABRAF). Anuário estatístico da ABRAF 2011. Brasília, 2011. 130 p.

BARBETTA, P. A. Estatística aplicada às Ciências Sociais. Florianópolis: Ed. da UFSC, 2006. 315 p.

BET, M. Análise da introdução do componente florestal em sistemas de produção representativos da região de Florianópolis, Santa Catarina. Florianópolis: Editora da UFSC, 1997. 134 p.

BRASIL. MINISTÉRIO DO MEIO AMBIENTE (MMA). Serviço Florestal Brasileiro. Florestas do Brasil em resumo 2010. Brasília: SFB, 2010. 143 p.

EMPRESA DE PESQUISA AGROPECUÁRIA E EXTENSÃO RURAL DE SANTA CATARINA (EPAGRI). Centro de Socioeconomia e Planejamento Agrícola. Síntese Anual da Agricultura de Santa Catarina 2009 -2010. Florianópolis: Epagri/Cepa, 2010. 315 p. 
FANTINI, A. C.; SIMINSKI, A. De agricultor a agricultor silvicultor: Um novo paradigma para a conservação e uso de recursos florestais no sul do Brasil. Agropecuária Catarinense, Florianópolis, v. 20, p. $16-18,2007$.

INSTITUTO BRASILEIRO DO MEIO AMBIENTE E DOS RECURSOS NATURAIS RENOVÁVEIS (IBAMA). DOF: Informação estratégica para a gestão florestal no Brasil: período 2007/2009. Brasília: Ibama, 2010, 56 p.

INSTITUTO BRASILEIRO DE GEOGRAFIA E ESTATÍSTICA (IBGE). Produto Interno Bruto dos Municípios 2003-2007. Comunicação Social. Rio de Janeiro. 2009. Disponível em: $<$ http://www.ibge.gov.brhome/presidencia/noticias/noticia_impressao.php?id_noticia=1520>. Acesso em: 05/03/2010.

INSTITUTO DE PLANEJAMENTO URBANO DE FLORIANÓPOLIS (IPUF). População por unidade espacial de planejamento (UEP). Florianópolis: PMF, 2002.

LEÃO, R. M. A floresta e o homem. São Paulo: Instituto de Pesquisas e Estudos Florestais, 2000. 448 p.

PROGR AMA DE DESENVOLVIMENTO DAS NAÇÕES UNIDAS (PNUD). Ranking do IDH-M dos municípios do Brasil. 2000. Disponível em: <http://www.pnud.org.br/atlas/tabelas/index.php>. Acesso em: 20/11/2009.

REITZ, R.; KLEIN, R. M.; REIS, A. Projeto madeira de Santa Catarina. Sellowia, Itajaí, v. 28, p. 1 - 320, 1978.

SCHUCH, C.; SIMINSKI, A.; FANTINI, A. C. Usos e potencial madeireiro do jacatirão-açu (Miconia cinnamomifolia (de candolle) Naudin) no litoral de Santa Catarina. Floresta, Curitiba, PR, v. 38, n. 4, p. 735 - 741, 2008.

SOBRAL, L.; VERÍSSIMO, A.; LIMA, E.; AZEVEDO, T.; SMERALDI, R. Acertando o Alvo 2: consumo de madeira amazônica e certificação florestal no Estado de São Paulo. Belém: Imazon, 2002. $72 \mathrm{p}$.

THOMÉ, N. 1949 - Ciclo da madeira: história da devastação da floresta da araucária e do desenvolvimento da indústria da madeira em Caçador e na região do Contestado no século XX. Caçador: Universal, 1995. $212 \mathrm{p}$. 